\title{
DETECTION OF HYBRIDS IN NATURAL POPULATIONS OF PICEA GlaUCA AND PICEA ENGELMANNII
}

\author{
MONIA S.H. HASELHORST $\bullet$ C. AlEX BUERKLE \\ UNIVERSITY OF WYOMING $\uparrow$ LARAMIE
}

\begin{abstract}
$\uparrow \quad$ ABSTRACT
The geographic borders between related species are often overlapping and much is unknown about the ecological and evolutionary dynamics between species in these regions. This is particularly true within long-lived forest trees such as conifers. The spruce species Picea glauca and Picea engelmannii were used in this study to elucidate the genetic dimension of their hybridization, as these species are ecologically divergent and are known to hybridize in nature. Opportunities for hybridization occur along elevational gradients where they cooccur, from northwestern Wyoming north through the central Rocky Mountains and British Columbia. This study was concentrated in the Central Rocky Mountains in Wyoming including the Greater Yellowstone Ecosystem. We found remarkable variation of genetic ancestry within and among geographic locations. Our genetic results provide evidence for a previously unrecognized, complex geographic mosaic for the interaction between these two species in this part of North America.
\end{abstract}

\section{$\downarrow \quad$ INTRODUCTION}

Species occupying the same geographical space provide opportunities for studying ecological and evolutionary influences on species diversity and adaptation to a changing climate (Sexton et al. 2009). The geographic borders between related species are often overlapping and are shaped by competition, hybridization and adaptation (Goldberg and Lande 2007; Sexton et al. 2009). There are major gaps in our knowledge about the ecological and evolutionary dynamics in how diversity is partitioned in space and in species in these overlapping regions, in particular within long-lived forest trees such as conifers (Neale and Ingvarsson 2008). Conifers are a large and highly

diverse group of gymnosperms that are distributed widely throughout the world with dominance in the northern hemisphere. Although the geographical ranges of North American conifers in general are well known, many questions remain about the zones where species come into geographic contact: whether they hybridize, how widespread hybrids are and how hybrids and parental species can be accurately identified (Daubenmire 1968; Mallet 2005; Burgarella et al. 2009). Hybridization and subsequent backcrosses (i.e., introgression) to parental species are known to occur between a number of conifer species (e.g., Picea glauca x P. engelmannii, Pinus pumila $\mathrm{x} P$. parviflora and Abies procera $\mathrm{x} A$. magnifica; for more examples see Jaramillo-Correa et al. 2009).

The spruce species Picea glauca and Picea engelmannii provide an attractive system for elucidating the genetic basis of the traits that are involved in adaptation, as these species are ecologically divergent and are known to hybridize in nature. P. glauca is a sub-arctic species and occurs in low elevation habitats across Canada, from the US border to the Yukon, Northwest Territories, Nunavut and in the USA from the northern parts of the Great Lakes to the New England states, in the intermountain West and in the Black Hills of South Dakota. P. engelmannii is a sub-alpine species that is distributed in western Canada and the USA, from Alberta and British Columbia to Arizona and New Mexico (Rajora and Dancik 2000, Figure 1). Opportunities for hybridization occur along elevational gradients where they co-occur, from northwestern Wyoming north through the central 
Rocky Mountains and British Columbia. Botanists have suggested that these two species hybridize in the central Rocky Mountains in the US, based on observed intermediate cone and needle morphology in some trees. However, the existence of hybrids in this region has not been confirmed, but can be verified objectively with molecular markers. Knowledge of hybrid occurrence and of finer-scale distributional information for parental species can play an important role in future management and decisions related to the maintenance of biodiversity, particularly in the context of a changing climate (Barton 2001; Rehfeldt 2004; Aitken et al. 2008; Ledig et al. 2010).

Hybrid zones occur when genetically distinct populations meet and reproduce, resulting in offspring with highly variable genotypes and phenotypes (Rieseberg et al. 1999; Lexer et al. 2005). Hybridization followed by introgression (backcross of a natural hybrid to one of the parental species or another hybrid) is a common occurrence in a hybrid zone (Anderson 1949; Mallet 2005; Lexer et al. 2004). Further, a hybrid zone may contain individuals that are the result of multiple generations of recombination and genetic variation that is directly influenced by selection in nature (Lexer et al. 2004; Mallet 2005). Therefore, comparisons among hybrid and parental populations illustrate the dynamics within and among natural populations and plant responses and relationships to environmental fluctuations.

Correct characterization of the genetic composition of parental species is essential in the detection of hybrids (Burgarella et al. 2009). Molecular markers (e.g., microsatellite DNA loci) are available to facilitate research on the genetics within spruce (e.g., Rungis et al. 2004; Pelgas et al. 2006).

Previous research on hybridizing spruce species has characterized some morphological (Weng and Jackson 2000), physiological and molecular marker differences (Rajora and Dancik 2000; Rehfeldt 2004; Ledig et al. 2004; Major et al. 2007; Barsi et al. 2009; Tollefsrud et al. 2009). However, much remains to be learned about the spatial and habitat distribution of these spruce species and their hybrids. This study is a first step toward developing a system in which hybrids can be used to learn about the genome interactions within natural zones of hybridization between these species.

The main objective for this study was to identify parental populations and hybrids between Picea glauca and Picea engelmannii by their genetic composition. Specifically we: 1) quantified genetic differences between the parental species to verify genetically distinct species, 2) identified populations with hybrids using genetic tools, and 3) studied the nature of genetic introgression between these species.

\section{$\uparrow \quad$ METHODS}

Needles were sampled from pure populations of Picea glauca and Picea engelmannii outside of the area of geographic sympatry ( $P$. glauca: Alaska, Ontario, northwest South Dakota; $P$. engelmannii: Arizona, southern Wyoming; Figure 1). Needles were sampled within zones of geographic contact from six different populations: Black Hills National Forest, Big Horn National Forest, Laramie

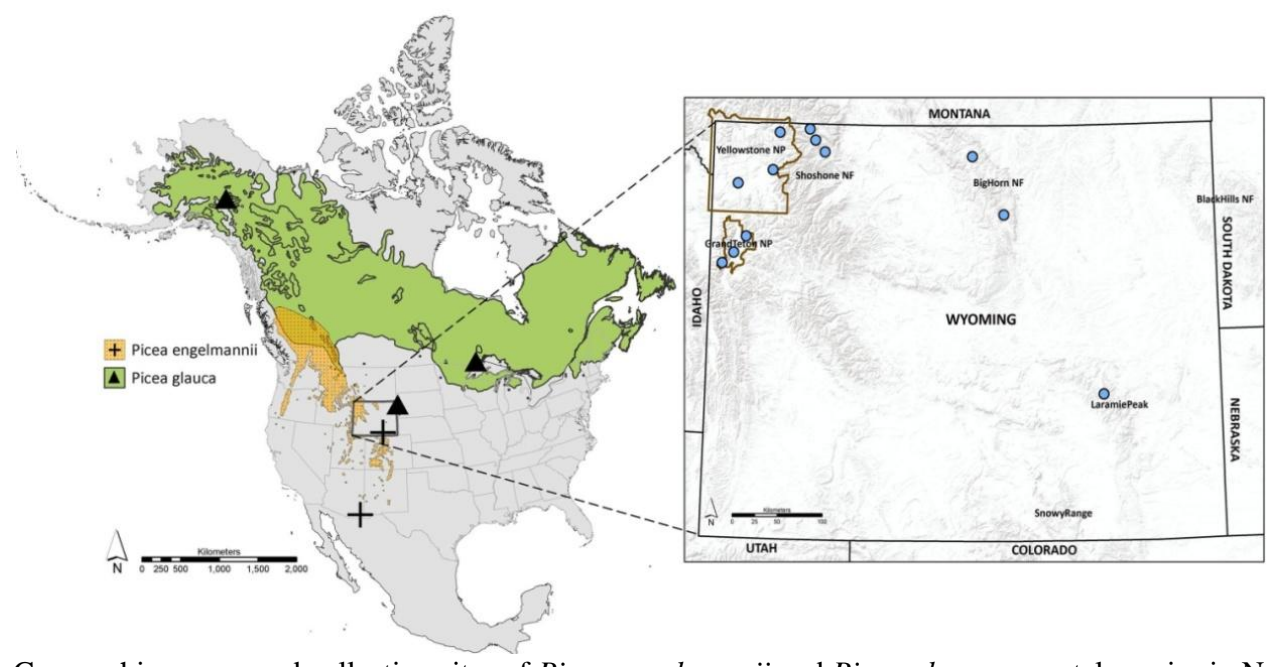

Figure 1. Left: Geographic ranges and collection sites of Picea engelmannii and Picea glauca parental species in North America (USGS). Right: Specific collection sites in Wyoming that were studied for presence of hybrids and parental species. 
Peak in Medicine Bow National Forest, Shoshone National Forest, Yellowstone National Park and Grand Teton National Park (Figure 1). DNA was extracted from a total of 336 individuals and 17 microsatellite markers were used to infer the frequencies of alleles in the parental forms $(n=84)$ to allow for the estimation of ancestry for all other individuals $(\mathrm{n}=252)$.

\section{$\uparrow \quad$ PRELIMINARY RESULTS}

We found remarkable variation of genetic ancestry within and among geographic locations (Figure 2). In particular, we found a complex geographic distribution of parental species and their hybrids. For example, evidently pure populations of $P$. engelmannii occur at Avalanche Peak in eastcentral Yellowstone National Park, whereas nearby populations in the northeastern section of the park contain individuals of both parental species and a variety of hybrids. More broadly, there are few or no hybrids in the southern portion of the Greater Yellowstone Ecosystem (GYE) and the frequency of hybrids increases towards the northeast of Yellowstone National Park. The most common parental species in the GYE is $P$. engelmannii. However, our results reveal individuals or smaller stands of evidently pure $P$. glauca at various sites within the GYE, in particular in the northeast of Yellowstone National Park and northern parts of Shoshone National Forest. To the east, in the Bighorn Mountains, both parental species and hybrids occur, whereas the Black Hills are occupied by P. glauca (as noted above).
These genetic results are consistent with our observation of highly variable and intermediate morphology in many trees. This implies that hybridization followed by introgression occurs between the parental species $P$. glauca and $P$. engelmannii in many of the studied populations, whereas other populations in the same region contain only one parental species, or one parental species and hybrids. The genetic results document a previously unrecognized complex geographic mosaic for the interaction between these two species in this part of North America.

\section{$\downarrow \quad$ MANAGEMENT IMPLICATIONS}

Based on our genetic observations, we have verified hybrids between $P$. glauca and $P$. engelmannii in the GYE and nearby mountain ranges in Wyoming. One of the challenges for species and hybrid identification in Picea stems from the narrow range of morphological differences among species or lineages. These objective genetic results can assist in delimiting lineages and recognizing parental and hybrid trees in the field. Proper inventories of species composition, or simple knowledge of the existence of hybrids within a geographic region, can aid future biodiversity assessments and management decisions.

For example, the GYE contains not only the two Picea species but is also home to their evolutionary and ecological interactions and their production of variable hybrid progeny. The outcomes for the parental species and hybrids within this region will be shaped by a changing climate and our results can facilitate long-term monitoring of their ranges and interactions.

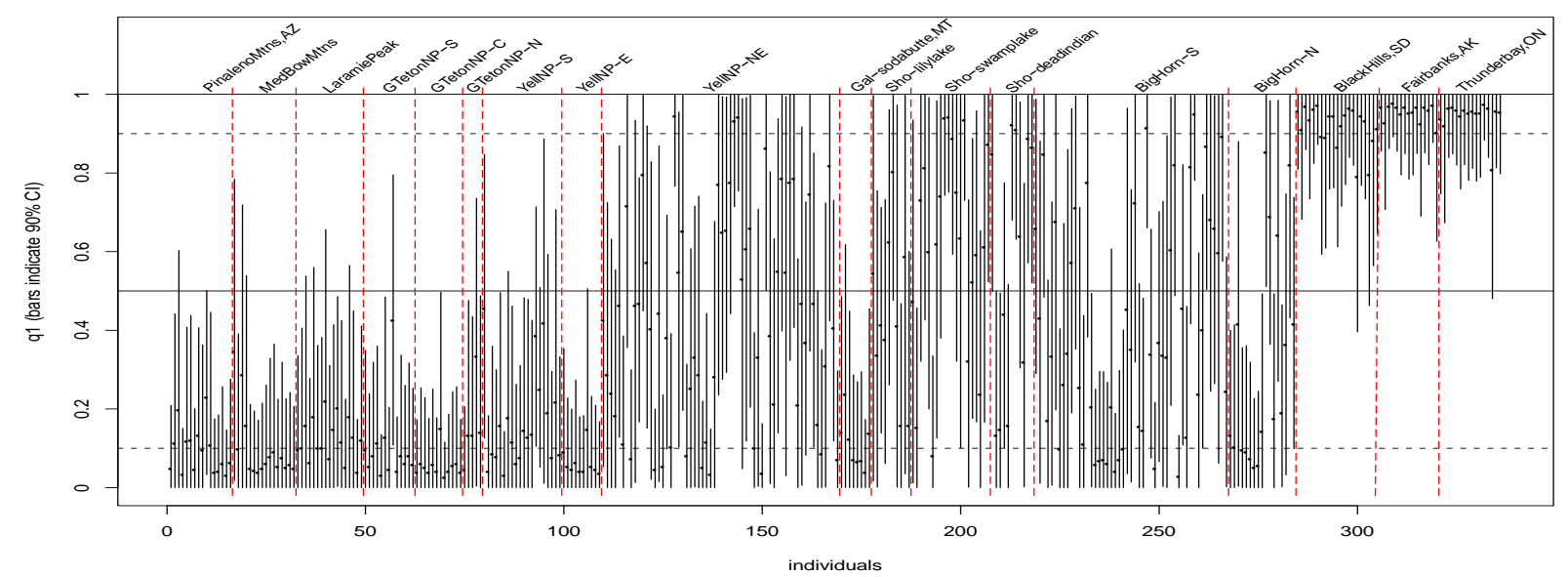

Figure 2. Point estimates of genetic ancestry (q; bars indicate $90 \%$ credible interval) of 336 individual trees of Picea engelmannii $(\mathrm{q}=0)$, Picea glauca $(\mathrm{q}=1)$ and hybrids (results from analyses in structure, Falush et al. 2003). Collection sites are indicated above the graph. Considerable variation in ancestry is evident within and among collection sites, suggesting that within this area of geographic overlap, the interaction of the two species varies extensively. 


\section{ACKNOWLEDGEMENTS}

In addition to support from the UW-NPS Research Station, this project has received funding from the Wyoming Native Plant Society, John W. Marr Memorial Ecology Fund, Shoshone National Forest and H.T. Northern Summer Fellowship in Botany.

\section{Literature CiTED}

Aitken SN, Yeaman S, Holliday JA, Wang T, CurtisMcLane S. 2008. Adaptation, migration or extirpation: climate change outcomes for tree populations. Evolutionary Applications. 1:95-111.

Anderson E. 1949. Introgressive Hybridization. John Wiley, New York.

Barsi DC, Major JE, Mosseler A, Campbell M. 2009. Genetic variation and control of chloroplast pigment concentrations and related needlelevel traits in Picea rubens, Picea mariana, and their hybrids: moisture and light environmental effects. Trees - Structure and Function. 23:555-571.

Barton NH. 2001. The role of hybridization in evolution. Molecular Ecology. 10:551-568.

Burgarella C, Lorenzo Z, Jabbour-Zahab R, et al. 2009. Detection of hybrids in nature: application to oaks (Quercus suber and $Q$. ilex). Heredity. 102:442-452.

Daubenmire R. 1968. Some geographic variations in Picea sitchensis and their ecological interpretation. Canadian Journal of Botany. 46:787-798.

Goldberg EE, Lande R. 2007. Species' borders and dispersal barriers. American Naturalist. 170:297-304.

Jaramillo-Correa JP, Beaulieu J, Khasa DP, Bousquet J. 2009. Inferring the past from the present phylogeographic structure of North American forest trees: seeing the forest for the genes. Canadian Journal of Forest Research. 39:286-307.
Ledig FT, Hodgskiss PD, Krutovskii KV, Neale DB, Eguiluz-Piedra T. 2004. Relationships among the spruces (Picea, Pinaceae) of southwestern North America. Systematic Botany. 29:275-295.

Ledig FT, Rehfeldt GE, Saenz-Romero C, FloresLopez C. 2010. Projections of suitable habitat for rare species under global warming scenarios. American Journal of Botany. 97:970-987.

Lexer C, Heinze B, Alia R, Rieseberg LH. 2004. Hybrid zones as a tool for identifying adaptive genetic variation in outbreeding forest trees: lessons from wild annual sunflowers (Helianthus spp.). Forest Ecology and Management. 197:49-64.

Lexer C, Rosenthal DM, Raymond O, Donovan LA, Rieseberg LH (2005) Genetics of species differences in the wild annual sunflowers, Helianthus annuus and $H$. petiolaris. Genetics. 169:2225-2239.

Major JE, Barsi DC, Mosseler A, Campbell M. 2007. Genetic variation and control of chloroplast pigment concentrations in Picea rubens, Picea mariana and their hybrids. I. Ambient and elevated $\mathrm{CO} 2$ environments. Tree Physiology. 27:353-364.

Mallet J. 2005. Hybridization as an invasion of the genome. Trends in Ecology \& Evolution. 20:229-237.

Neale DB, Ingvarsson PK. 2008. Population, quantitative and comparative genomics of adaptation in forest trees. Current Opinion in Plant Biology. 11:149-155.

Pelgas B, Beauseigle S, Achere V, Jeandroz S, Bousquet J, Isabel N. 2006. Comparative genome mapping among Picea glauca, $P$. mariana $x P$. rubens and $P$. abies and correspondence with other Pinaceae. Theoretical and Applied Genetics. 113:13711393.

Rajora O, Dancik B. 2000. Population genetic variation, structure, and evolution in Engelmann spruce, White spruce, and their natural hybrid complex in Alberta. Canadian Journal of Botany. 78:768-780. 
Rehfeldt G. 2004. Interspecific and intraspecific variation in Picea engelmannii and its congeneric cohorts: biosystematics, genecology and climate change. General Technical Report RMRS-GTR-134, U.S. Department of Agriculture, Forest Service, Rocky Mountain Research., Fort Collins, CO.

Rieseberg LH, Whitton J, Gardner K. 1999. Hybrid zones and the genetic architecture of a barrier to gene flow between two sunflower species. Genetics. 152:713-727.

Rungis D, Berube Y, Zhang J, et al. 2004. Robust simple sequence repeat markers for spruce (Picea spp.) from expressed sequence tags. Theoretical and Applied Genetics. 109:12831294.
Sexton JP, McIntyre PJ, Angert AL, Rice KJ. 2009. Evolution and Ecology of Species Range Limits. Annual review of ecology, evolution and systematics. 40:415-436.

Tollefsrud MM, Brochmann C, Sperisen C. 2009. Paternal introgression from Siberian spruce (Picea obovata) to Norway spruce (Picea abies): tracing pollen and seed flow with chloroplast and mitochondrial DNA, in manuscript.

Weng C, Jackson S. 2000. Species differentiation of North American spruce (Picea) based on morphological and anatomical characteristics of needles. Canadian Journal of Botany. 78:1367-1383. 